Cita bibliográfica: Lin, W. y Tarí, J. J. (2020). Criterios de calidad clave para mejorar la gestión de las empresas colaborativas turísticas en España. Investigaciones Turísticas (19), pp. 73-103. https://doi.org/10.14198/INTURI2020.19.04

\title{
Criterios de calidad clave para mejorar la gestión de las empresas colaborativas turísticas en España
}

\section{Key quality criteria to improve management in collaborative tourism companies in Spain}

Wei Lin (iD, Universidad de Alicante, España mrwilllin@gmail.com

Juan José Tarí iD, Universidad de Alicante, España ii.tari@ua.es

\section{RESUMEN}

Dada la importancia del turismo para la economía española y para la economía colaborativa, las empresas colaborativas turísticas en España necesitan un sistema de gestión que les permita planificar, controlar y mejorar sus actividades. Este trabajo analiza el sistema de gestión de las empresas de turismo colaborativo en España a partir de los principios o dimensiones de la calidad e identifica los criterios clave para mejorar su gestión. Para conseguir estos objetivos, se realiza una investigación empírica de una plataforma de coche compartido y de una empresa tradicional. Los resultados indican que, aunque las plataformas colaborativas mantienen una alta satisfacción de los usuarios, existen ciertos problemas que dificultan su gestión. A partir de la comparación de los resultados de ambas empresas el trabajo señala los criterios clave para mejorar su gestión.

Palabras clave: Economía colaborativa; Turismo colaborativo; Gestión de calidad; Gestión medioambiental; Coche compartido

\begin{abstract}
Given the importance of tourism for the Spanish economy and the sharing economy, Spanish collaborative tourism companies need a management system that allows them to plan, control and improve their activities. This paper analyses the management system of the collaborative tourism companies in Spain, based on the principles or dimensions of quality management. It also identifies the new criteria for the sector. In order to achieve these objectives, an empirical analysis of a carsharing platform and a traditional company is carried out. The results show that although the collaborative platforms maintain high user satisfaction, some problems remain
\end{abstract}


unsolved. By comparing the results between these two firms, the study proposes fundamental quality criteria for improving the management system in collaborative tourism companies.

Keywords: Sharing Economy; Collaborative Tourism; Quality Management; Environmental Management; Carsharing

\section{INTRODUCCIÓN}

El modelo colaborativo se ha convertido en una fuerza no desdeñable en el nuevo ciclo del desarrollo mundial, donde el sector turístico tiene un peso considerable. Los cinco sectores principales de la economía colaborativa son: el turismo, el coche compartido, las finanzas, la intermediación laboral y la música y video en streaming (PwC, 2015). Estos cinco sectores podrían alcanzar unos ingresos de 335 mil millones de dólares en 2025 a nivel mundial, superando el PIB de Irlanda de 2017 (World Bank, 2018). Entre ellos, el turismo y el coche compartido son los dos sectores más importantes y representativos tanto para la economía colaborativa como para el turismo colaborativo.

Dada la importancia del turismo para la economía española, que contribuyó al 11,7\% del PIB y supuso el 12,8\% de puestos de trabajo en 2017 (INE, 2018), y para la economía colaborativa, las empresas colaborativas turísticas en España necesitan desarrollar una gestión correcta de sus actividades para sobrevivir. Aunque la comunidad académica ha analizado la economía colaborativa desde distintos aspectos, no se han encontrado estudios relacionados con el sistema de gestión de las empresas de la economía colaborativa en general y de las empresas colaborativas turísticas en particular. Este trabajo cubre esta laguna de la literatura.

Por ello, los objetivos de este trabajo son: a) analizar la situación de la gestión de las empresas de turismo colaborativo en España a partir de los principios o dimensiones de la calidad, y b) identificar los criterios clave para mejorar su gestión.

Para conseguirlos, en primer lugar, se hace una revisión de la literatura sobre el turismo colaborativo y el sistema de gestión. A continuación, a través de una serie de cuestionarios y entrevistas de una empresa colaborativa turística y una tradicional turística, se analiza la situación de la gestión de las empresas de turismo colaborativo y se comparan los resultados obtenidos para, posteriormente, identificar los criterios clave para mejorar la gestión del modelo colaborativo teniendo en cuenta las dimensiones de la calidad. Finalmente, se muestran las conclusiones, limitaciones del trabajo y futuras investigaciones.

\section{TURISMO COLABORATIVO Y CALIDAD}

\subsection{Turismo colaborativo en España}

Para definir una empresa colaborativa se deben tener en cuenta dos elementos esenciales: el consumo colaborativo y la plataforma online. El consumo colaborativo es una actividad que desarrollan los particulares para coordinar la adquisición y la distribución de un recurso a través de cierta forma de compensación (Belk, 2014; Botsman \& Rogers, 2010; Hamari, Sjöklint, \& Ukkonen, 2016), por lo que los participantes principales de la economía 
colaborativa son los particulares. La plataforma online describe el canal de la actividad, que es la diferencia esencial entre la economía colaborativa y las actividades tradicionales de compartir, como compraventa de artículos de segunda mano en tiendas, casas de particulares u otros lugares físicos.

Sharing España (2017), colectivo de empresas vinculadas a la economía colaborativa que están integradas en Adigital (Asociación Española de la Economía Digital), ha creado siete categorías para clasificar a las empresas colaborativas: Alojamiento, Finanzas, Movilidad y Transporte, Tareas y Trabajo, Consumo, Conocimiento y Educación, y Gastronomía. Entre ellas, se observa una amplia integración del modelo en el sector turístico, donde se encuentran las plataformas más conocidas: Airbnb, Couchsurfing, BlaBlaCar, Amovens, TripAdvisor, Trip4Real (Airbnb Trips) y EatWith. De este modo, se considera que el desarrollo del turismo colaborativo representa a la economía colaborativa.

La economía colaborativa ha surgido para romper y cambiar el mundo (The Economist, 2013; Walsh, 2011), y a pesar de su expansión a nivel mundial nació con controversias. En este sentido, se distinguen tres grupos relacionados contra el turismo colaborativo:

1. Los defensores de la economía tradicional. El crecimiento de las empresas colaborativas amenaza a las tradicionales (Zervas, Proserpio, \& Byers, 2013). Los trabajadores o empresarios de estas últimas señalan los daños económicos causados por la nueva economía, sufriendo la competencia desleal (El Confidencial, 2017; Franco \& Gómez, 2019; TeleMadrid, 2019). Muchos participantes aprovechan el término "economía colaborativa" como un pretexto para evitar competir con las mismas condiciones que los proveedores reglados (HOSBEC, 2018). En el caso del mercado de alquiler turístico de Alicante, el $75 \%$ de los alojamientos de la ciudad en Airbnb se alquilan completos (AirDNA, 2019).

2. Los ciudadanos molestos, especialmente por Airbnb. A los vecinos les influye la incorporación de los turistas al barrio. Las molestias no sólo vienen del cambio del ambiente, sino también por problemas de seguridad. Los vecinos suelen estar incomodos con los desconocidos, en particular, con los que se quedan pocos días (Minifie \& Wiltshire, 2016).

3. Los usuarios insatisfechos. Por un lado, la mayoría de las plataformas colaborativas llevan pocos años operando y tienen experiencias limitadas. Por otro lado, cuantos más usuarios tengan, mayor diversidad existe y más difícil es satisfacer a los clientes. En el caso de Blablacar, 8 empleados $^{1}$ frente a 3,5 millones de usuarios en España (BlaBlaCar, 2018), y su rival Amovens, $33^{2}$ frente a 1,5 millones (Amovens, 2018). Esta gran disparidad causa la insatisfacción. Además, el mercado colaborativo se ha convertido en un oligopolio, lo ha confirmado el caso de Didi. La Uber de China, que así suele llamarle la prensa, hasta 2017, consiguió un 92,5\% del mercado del sector colaborativo de movilidad en China. Desplazarse con Didi ya no es una opción económica y eficiente como

1. El número de empleados fue facilitado por la responsable de comunicación de BlaBlaCar España y Portugal el día 24 de abril de 2018. Las 8 personas se encargan de marketing, atención de cliente y administración del mercado ibérico.

2. El dato fue facilitado por la responsable de personal de Amovens el día 7 de mayo de 2018 por email. 
cuando se inició, ya que incluso es más cara que los taxis. Los pasajeros demandan el regreso del taxi tradicional (Kriptón Inteligencia, 2018).

Las administraciones manifiestan distintas actitudes hacia el nuevo modelo, incluso a veces contradictorias. Países como el Reino Unido, apoyan e impulsan el modelo colaborativo; por el contrario, en Bélgica, Francia, Alemania, Italia y Holanda, las regulaciones muchas veces dificultan la economía colaborativa, por ejemplo, sin una licencia profesional, ofrecer servicio como conductor en las plataformas se considera ilegal (Knowledge@Wharton, 2016). Hay que tener en cuenta que las empresas colaborativas son internacionales o transregionales en su mayoría. Deben modificar su gestión y sus operaciones para adaptarse a las distintas regulaciones. Se puede citar que la empresa colaborativa más valorada en el mundo, Uber, no opera «colaborativamente» en España (del Castillo, 2017).

De forma colectiva, las aplicaciones y páginas web, y los servicios realizados por los usuarios proveedor ${ }^{3}$, influyen en la imagen de la plataforma. Además de mejorar sus propios productos, las empresas colaborativas también necesitan impulsar la calidad de sus servicios. En el caso de Amovens, el grupo de conductores alcanzó los 178.080 (Amovens, 2018), en cambio, un $82,6 \%$ de todas las empresas españolas solo tienen 2 o menos empleados, solo un $0,39 \%$ tienen una plantilla igual o superior a 100 personas (INE, 2019). Se puede decir que la dirección de Amovens tiene una de las gestiones más difíciles entre las empresas españolas.

En resumen, las empresas del turismo colaborativo en España, desde el punto de vista externo, necesitan optimizar las relaciones con sus grupos de interés para crear un ambiente favorable para su desarrollo. Desde el punto de vista interno, la dirección debería mantener una buena calidad en sus servicios o productos y maximizar su productividad con un número de empleados limitado.

\subsection{Gestión de Calidad y Medio Ambiente}

Para mejorar esta gestión, las empresas colaborativas pueden adoptar sistemas de gestión. A nivel mundial, los dos sistemas de gestión más implantados en las empresas son los de gestión de calidad (GC en adelante) y de gestión del medio ambiente (GMA en adelante). Entre ellos destacan los modelos Malcolm Baldrige, EFQM, Deming, ISO 9001 y la marca Q de calidad turística para la GC, y los modelos ISO 14001 y el reglamento EMAS para la GMA.

Los sistemas de GC y de GMA mantienen la misma finalidad, que la empresa obtenga una mejor eficiencia y una mayor rentabilidad. Además, los dos comparten gran parte de la estructuración del sistema y la metodología de operación. Sin mencionar que después de años de desarrollo, la GC y la GMA se han integrado en muchos casos en un sistema de gestión (GCMA en adelante) en muchas organizaciones (Angell \& Klassen, 1999; Curkovic, 2003; Klassen \& McLaughlin, 1993; Molina-Azorín, Tarí, Claver-Cortés, \& López-Gamero, 2009).

Ambos sistemas tienen efectos positivos en la satisfacción de clientes, la reducción del coste, la diferenciación y la mejora de la imagen y la eficiencia organizacional (Abad,

3. Los usuarios proveedor son los que ofrecen los servicios o productos en las plataformas. 
Dalmau, \& Vilajosana, 2014; Bernardo, Simon, Tarí, \& Molina-Azorín, 2015; Crowder, 2013; de Oliveira, 2013; Ferreira Rebelo, Santos, \& Silva, 2014; Karapetrovic \& Casadesús, 2009; Santos, Mendes, \& Barbosa, 2011; Simon \& Douglas, 2013; Simon, Karapetrovic, \& Casadesus, 2012; Simon, Karapetrovic, \& Casadesús, 2012; Wagner, 2007). Además, la integración en sí misma también reduce costes y mejora la comunicación y la gestión (Beckmerhagen, Berg, Karapetrovic, \& Willborn, 2003; Molina-Azorín et al., 2009; Rodríguez \& Ricart, 2000; Wilkinson \& Dale, 1999; Zeng, Tian, \& Shi, 2005; Zutshi \& Sohal, 2005). Esta mejora de la gestión es un aspecto básico para las empresas colaborativas que se puede conseguir a través de la GC.

\subsection{Implantación del Sistema de Calidad para el Turismo Colaborativo}

A pesar de los problemas y retos del nuevo modelo, la economía colaborativa ha mostrado ser un sector fuerte y puede ser una solución eficaz para el desarrollo socioeconómico. China, uno de los países más proactivos, se ha decidido a desarrollar la economía colaborativa como una estrategia estatal (Li, 2017). El fuerte respaldo político ha producido resultados magníficos: el ingreso total del modelo colaborativo alcanzó 4,92 billones de yuanes $(646,86$ mil millones de euros ${ }^{4}$ ) en el año 2017 con un crecimiento del 47,2\% respecto al año anterior; empleó a 7,16 millones de personas, entre ellos, 1,31 millones son nuevos empleos, y ocupó aproximadamente un $9,7 \%$ del total de los puestos nuevos en las ciudades en China; entre los 700 millones de participantes, 70 millones juegan el papel de proveedores de servicio (Centro de Investigación de la Economía Colaborativa del Centro Estatal de Información Chino \& Comisión de la Economía Colaborativa de Sociedad de Internet de China, 2018). En España, también hay un alto interés por la nueva economía, el $53 \%$ de la población participaría en actividades colaborativas, por encima de la media de Europa (44\%) (Nielson, 2014). Más que una necesidad para desarrollar la economía, el modelo colaborativo es una selección de la población.

El modelo colaborativa también ha generado impactos positivos al medio ambiente. El desarrollo de coche compartido permite reducir las emisiones de $\mathrm{CO}_{2}$, porque rebaja el consumo de combustible per cápita y el número de coches corrientes por las carreteras, además ayuda a los participantes a tener comportamientos más ecológicos (Cervero, Golub, \& Nee, 2007; Yin, Liu, Coulombel, \& Viguié, 2018). En España, compartir vehículos a través de BlaBlaCar y Amovens supuso un ahorro de emisiones de 2 millones de toneladas de $\mathrm{CO}_{2}$ en 2016 aproximadamente (Sharing España, 2017), y la ocupación media por coche ha sido de 2,8 personas respecto a 1,7 de promedio en Europa (BlaBlaCar, 2018). La gran influencia positiva medioambiental también es uno de los motivos por los cuales los consumidores participan en la economía colaborativa (BlaBlaCar, 2018; Hamari et al., 2016).

Esto indica que los benificios esperados del turismo colaborativo también son los objetivos principales de la GCMA. Además, un sistema de GCMA puede responder a los problemas y retos del nuevo modelo: a) la mejora de la imagen y las relaciones públicas, lo que suavizaría la alta tensión entre las plataformas y los manifestantes, y se crearía un ambiente

4. Tipos de cambio: CNY/EUR=0,13, 9 de febrero, 2019. 
más tolerante, y b) el aumento de la eficiencia aseguraría mejores resultados económicos y medioambientales.

Estas ideas señalan que las empresas colaborativas turísticas pueden beneficiarse de implantar un sistema de calidad para mejorar su gestión, la calidad y la protección del medio ambiente.

\section{METODOLOGÍA}

\subsection{Muestra}

Dado la aplicación del modelo colaborativo en la economía en numerosos sectores, en este trabajo se elige el sector coche compartido, por la importancia del sector de transporte en el turismo y su entorno jurídico relativamente estable. En particular, se elige compartir viaje entre diferentes municipios ${ }^{5}$, que ya había sido reconocido como actividad legal en España, según el Juzgado de lo Mercantil №02 de Madrid (2017). Entre las empresas identificadas por Sharing España (2017) y Beltran Cangròs (2018), según su mercado principal y el tamaño, se selecciona Amovens como muestra. La razón de la exclusión de la más famosa, BlaBlaCar, era porque su cuerpo principal está en Francia. Además, una empresa tradicional ha sido escogida como muestra de comparación, Lucentum Autos, por operar en una actividad aproximada.

Amovens, fundada en 2009, es una de las dos principales plataformas de coche compartido en España. Se fusionó con GoMore en 2015 y establecieron su sede en Copenhague. Después de un periodo de cambios continuos, la oficina de Madrid está formada por un equipo de 33 personas. Ellos ejecutan la mayoría de las funciones de la plataforma, salvo la programación que se encarga la oficina de Copenhague. Además del coche compartido (compartir viaje), Amovens también opera en el alquiler de coche entre particulares y renting, aunque los dos últimos negocios no se incluyen en este trabajo. Entre los departamentos asociados a la línea de coche compartido, en Amovens se ha contactado con cuatro directivos y un empleado que respectivamente son: responsable de personal, responsable de atención al cliente, responsable de marketing digital, responsable de producto y analista de negocios.

Lucentum Autos, fundada en 2003, es una empresa alicantina con sede en Mutxamel. Se dedica a su negocio único de alquiler de coche con conductor (VTC). La empresa dispone de una flota de 16 coches (mayo de 2018), que ampliará a 21 en el corto plazo, y cuenta con 24 personas. Son cuatro socios, una administrativa y diecinueve conductores, se sumarán de ocho a diez personas más según su plan de expansión ${ }^{6}$.

Además de la información de estas empresas, se recoge información de los usuarios del coche compartido, tanto de conductores como de pasajeros.

5. Por las restricciones administrativas, se excluyen el sector donde opera Uber.

6. Los datos fueron facilitados por el socio y consejero delegado de Lucentum Autos por email el día 10 de mayo de 2018. 


\subsection{Recogida de Datos}

\subsubsection{Empresas}

El cuestionario a empresas mide el nivel de implantación de las prácticas de la gestión de calidad a partir de AEC (1997) y teniendo en cuenta las ocho dimensiones de la gestión de la calidad (Molina-Azorín et al., 2009): liderazgo, personal, planificación, información y análisis, procedimientos, proveedores, grupos de interés y productos/servicios (ver Tabla 1). Se establece una escala de Likert de 0 a 4, donde 0 significa "prácticamente no se realiza/definitivamente no", y 4 "se realiza siempre y de forma total/definitivamente sí». Sirve para ambas empresas con pocas modificaciones debido a las diferencias objetivas entre las muestras (para Amovens, ver Anexo 1, y para Lucentum Autos, ver Anexo 2).

Tabla 1: Distribución de preguntas para empleados Amovens y Lucentum Autos

\begin{tabular}{|c|c|c|}
\hline DIMENSIÓN & $\begin{array}{l}\text { PREGUNTAS } \\
\text { RELACIONADAS } \\
\text { (Anexo 1\&2) }\end{array}$ & $\begin{array}{c}\text { PREGUNTA } \\
\text { REPRESENTATIVA }\end{array}$ \\
\hline Liderazgo & $6,8,16$ & $\begin{array}{l}\text { 8. ¿La dirección también participa en las } \\
\text { actividades de la mejora? }\end{array}$ \\
\hline Personal & $\begin{array}{l}1,2,3,4,5,7,11,17,18 \\
19^{7}, 26\end{array}$ & $\begin{array}{l}\text { 4. ¿Tenemos canales para dar sugerencias a la } \\
\text { dirección fácilmente? }\end{array}$ \\
\hline Planificación & $1,6,12,30$ & $\begin{array}{l}\text { 30. ¿Estamos preparando para obtener algún } \\
\text { certificado de gestión de calidad o medio } \\
\text { ambiente, por ejemplo, ISO9001, ISO 14001? }\end{array}$ \\
\hline Información y Análisis & $10,17,23,29$ & $\begin{array}{l}\text { 23. ¿Puedo encontrar datos internos y } \\
\text { externos necesarios para mi trabajo de forma } \\
\text { conveniente y ágil? }\end{array}$ \\
\hline Procedimientos & $10,20,21$ & $\begin{array}{l}\text { 20. ¿Podemos realizar todos los procesos de } \\
\text { forma digital? }\end{array}$ \\
\hline Proveedores & 24,25 & $\begin{array}{l}25 . \text { ¿No sólo evaluamos la calidad de } \\
\text { proveedores sino también los aspectos } \\
\text { relacionados con el medio ambiente de los } \\
\text { proveedores? }\end{array}$ \\
\hline Grupos de Interés & $\begin{array}{l}9,13,14,15,16,19,26, \\
27,28,29\end{array}$ & $\begin{array}{l}\text { 28. ¿Tratamos la mejora de la satisfacción de } \\
\text { los usuarios como el objetivo significativo de la } \\
\text { empresa? }\end{array}$ \\
\hline Productos / Servicios & 22,29 & $\begin{array}{l}\text { 29. ¿Tenemos en cuenta las necesidades de los } \\
\text { usuarios, la administración, los proveedores o } \\
\text { los ciudadanos afectados al diseñar la APP y los } \\
\text { servicios? }\end{array}$ \\
\hline
\end{tabular}

7. Como los conductores son los prestadores del servicio reales, aquí se trata los conductores como empleados alejados, al calcular la evaluación de la dimensión de Personal. 
En primer lugar, los entrevistados cumplimentaron el cuestionario (ver Anexos 1 y 2) $y$, en segundo lugar, se llevaron a cabo entrevistas para confirmar y ampliar sus respuestas al cuestionario. Por ejemplo, en la entrevista se preguntaba lo siguiente: « ¿Podría indicarme un ejemplo de la pregunta $X$ ?». Además, la entrevista sirvió para conocer al encuestado, sus conocimientos de la empresa, del negocio, y de temas relacionados con la gestión de calidad y medio ambiente. Estas entrevistas fueron presenciales en el lugar de trabajo de los entrevistados. De este modo, el proceso de recogida de datos de las dos empresas se realiza siguiendo las siguientes etapas:

1. El 26 de abril de 2018, en la oficina de Amovens en Madrid, se realizaron cinco encuestas y cuatro entrevistas. Uno de los encuestados no podía presentarse para la entrevista en esa fecha por una incidencia, y cumplimentó el cuestionario de forma digital a posteriori.

2. El 10 de mayo de 2018 , en la oficina de Lucentum Autos en Mutxamel, se realizaron doce encuestas y tres entrevistas. Por la dificultad para unir a todos los empleados en la oficina, las encuestas se realizaron a través de Google Formularios.

Además, se entrevistó a la responsable de comunicación de BlaBlaCar España y Portugal el día 24 de abril de 2018, en su oficina en Madrid. La entrevista sirvió para conocer la plataforma BlaBlaCar, su número de empleados y las funciones principales del equipo en España.

\subsubsection{Conductores y Pasajeros}

Los conductores son quienes prestan el servicio. En Lucentum Autos son empleados que conforman el cuerpo principal de la empresa, en Amovens y otras plataformas colaboran como usuarios proveedor. Las preguntas del cuestionario utilizado para ellos (ver Anexo 3) se enfocan en la conexión con la empresa, la percepción de su papel, los conocimientos de la GCMA y su proactividad (ver Tabla 2).

Tabla 2: Distribución de preguntas para conductores

\begin{tabular}{|l|l|l|l|}
\hline \multirow{2}{*}{ ENFOQUE } & \multicolumn{2}{|c|}{ PREGUNTAS RELACIONADAS } & \multicolumn{1}{|c|}{$\begin{array}{c}\text { PREGUNTA } \\
\text { REPRESENTATIVA }\end{array}$} \\
\cline { 2 - 3 } & $\begin{array}{c}\text { Conductores De } \\
\text { PP.CC. } \\
\text { (Anexo 3) }\end{array}$ & $\begin{array}{c}\text { Conductores De } \\
\text { Lucentum Autos } \\
\text { (Anexo 2) }\end{array}$ & \multicolumn{1}{|c|}{$\begin{array}{c}\text { 2. ¿Mi comportamiento es clave para } \\
\text { la plataforma? }\end{array}$} \\
\hline $\begin{array}{l}\text { Percepción de su } \\
\text { papel }\end{array}$ & $1,2,12$ & 31,32 & $\begin{array}{l}\text { 6. ¿ंTenemos canales para dar } \\
\text { sugerencias a la plataforma? }\end{array}$ \\
\hline $\begin{array}{l}\text { Conexión con la } \\
\text { empresa }\end{array}$ & $3,6,7$ & 4,11 & $\begin{array}{l}\text { 9. ¿Tiene alguna característica de la } \\
\text { aplicación que sirva para la mejora de } \\
\text { medio ambiente? }\end{array}$ \\
\hline $\begin{array}{l}\text { Conocimiento de la } \\
\text { GCMA }\end{array}$ & 4,9 & 1,22 & $\begin{array}{l}\text { 8. ¿Me gustaría tener más conexión } \\
\text { con la plataforma? }\end{array}$ \\
\hline Proactividad & $5,8,10,11$ & 2,33 & \multicolumn{2}{|l}{} \\
\hline
\end{tabular}


Por la dificultad de localizar los usuarios offline, se difundió de forma online, a través de la aplicación Google Formularios. Todas las preguntas para los conductores y los pasajeros (ver Anexo 4), se realizaron con el mismo formulario, donde se incluyeron también algunas preguntas complementarias, como, por ejemplo, «indica la diferencia entre BlaBlaCar y Amovens» (para ver estas preguntas complementarias y el diseño del formulario ver Anexo 5).

Del 1 al 17 de mayo de 2018 tuvo lugar la difusión y recepción de encuestas. Se obtuvieron 46 respuestas. Para este trabajo, se recogieron 21 de ellas para el análisis que son siete respuestas de conductores y diecinueve de pasajeros (cinco personas desempeñan ambos papeles). Las excluidas son de usuarios del alquiler de coche, plataformas de otros países y no usuarios, sus respuestas no han sido analizadas para este artículo.

\section{RESULTADOS}

\subsection{Gestión de las empresas de turismo colaborativo a partir de los principios de calidad}

En la Figura 1 se observa la media de las respuestas (de Anexos 1 y 2) obtenidas de los empleados de Amovens y Lucentum Autos con relación a los principios o dimensiones de la calidad (ver Tabla 1). En global, Lucentum Autos ha obtenido una mejor puntuación, aunque Amovens muestra una mejor gestión en liderazgo, personal, procedimientos y grupos de interés. A continuación, se detalla la situación de los principios o dimensiones de la gestión de la calidad para cumplir con el primer objetivo de este trabajo.

Figura 1: Comparación de resultados de empleados

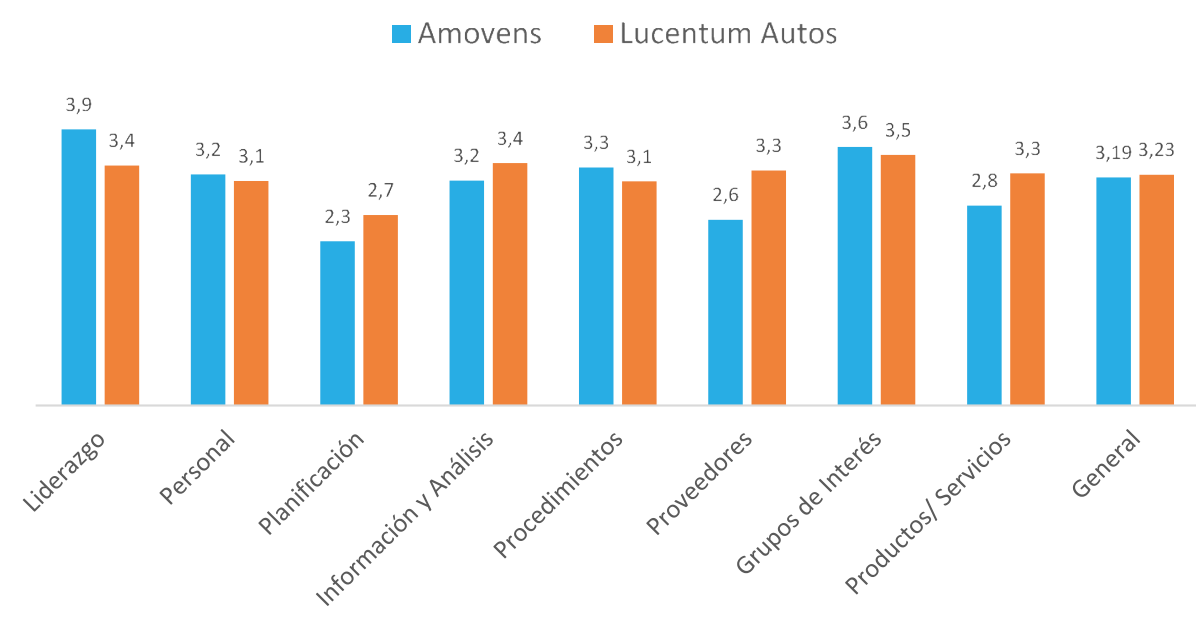

\subsubsection{Liderazgo y Personal}

Según la Comisión Europea (2014) Amovens y Lucentum Autos son identificadas como pequeñas empresas bajo la categoría de PYME. Derivado del tamaño reducido, los empleados mantienen una relación estrecha con los directivos. Los empleados muestran el mayor reconocimiento de la dirección por su participación en las actividades operativas, conocen los 
procedimientos asociados a su trabajo y sus objetivos. Se evalúan los resultados del trabajo en cuestión a sus ingresos de forma directa o indirecta. Además, en el caso de Lucentum Autos, la evaluación de los pasajeros ha sido mencionada como un aspecto crítico.

Empleado de Amovens (E.A. en adelante): «Evaluamos los resultados de trabajo de cada uno... No se refleja directamente en su salario, pero es importante a la hora de promoción.»

Empleado de Lucentum Autos (E.L. en adelante): «Cada semana, miramos las opiniones de clientes... comunicamos con todos... especialmente los problemas. Se premia a los empleados por rendimiento personal, especial cuidado y defensa de la imagen de la empresa y valoraciones de nuestros clientes.»

En Amovens, el nivel de satisfacción de los empleados se evalúa a través de un sistema formal, en cambio, en Lucentum es de una forma más informal.

E.A.: «Tenemos un programa, Happiness level (Nivel de felicidad), para evaluar la satisfacción a través de un cuestionario anónimo cada mes. La directora de personal se encarga de coordinar la evaluación, comunicar los resultados a la dirección y los empleados, y hacer el plan de mejora.»

E.L.: «Hablamos cada día cara a cara, damos sugerencias directamente a la dirección, en persona.»

Amovens ofrece distintos programas de formación que cubren las necesidades profesionales y personales de los empleados. En cambio, en Lucentum Autos apenas se ofrece formación, aparte de las relativas al trabajo y cuando consideran que es necesario.

E.A.: «Recogemos las necesidades de formación de cada empleado, y se eligen las más importantes y más demandadas. De momento, tenemos cursos de inglés para empleados, técnicas de presentación para los directivos.»

E.L.: "Se forma a los conductores en todas las áreas que van a desarrollar cuando sea necesario.»

Liderazgo y personal son los dos componentes clave para el éxito de la gestión (MolinaAzorín et al., 2009). Amovens tiene una concepción más moderna, avanzada y clara de la formación y la satisfacción del equipo. La dirección considera que la formación no solo sirve para mejorar la eficiencia, sino también para que los empleados puedan obtener un mejor desempeño. En cambio, en Lucentum Autos la formación solo ha sido considerada como una herramienta para solucionar problemas concretos.

\subsubsection{Planificación}

Ninguna de las dos empresas ha implantado un sistema de gestión certificado, a pesar de que han establecido políticas y procedimientos orientados a la mejora de la calidad. 
E.A.: "Disponemos de un sistema de gestión interno, este sistema no está certificado por ninguna de las instituciones certificadoras. [...] No es necesario (tener los certificados).»

E.L.: «Todavía no tenemos ninguno, pero estamos preparándonos para el certificado Q e ISO 9001.»

En la pregunta cinco "¿Se evalúa y recompensa los resultados sobre la calidad y medio ambiente?", se encuentra el mayor desacuerdo entre compañeros en ambas empresas ${ }^{8}$. En un sistema de gestión, establecer ciertas políticas e informarlas a la plantilla, es uno de los criterios más importantes. Si un empleado no puede tener una idea clara sobre la remuneración, que suele ser el tema más sensible, tendría menos conocimientos sobre otros asuntos.

Respecto al tema del medio ambiente, salvo la separación y reciclaje de basuras destacada por un administrativo de Lucentum Autos, la gestión del medio ambiente ha sido ignorada en ambas organizaciones.

Tener un certificado no es el objetivo para implantar un sistema de gestión. Amovens incluso muestra la desconfianza en los certificados. No obstante, que no esté de acuerdo con el proceso de certificación no indica que no se preocupe por implantar un sistema de gestión cumpliendo con los principios de la gestión de la calidad para planificar, controlar y mejorar sus actividades.

Como resumen en ambas empresas, las notas más bajas son para la planificación. Por parte de los empleados de Amovens y de Lucentum Autos, la planificación también ha sido identificada como un punto débil de su gestión.

\subsubsection{Grupos de Interés}

Amovens recibe la evaluación de pasajeros a través de su propia aplicación, Lucentum Autos la recibe por el canal de su distribuidor principal. Debido al volumen de clientes, Lucentum tiene un mejor conocimiento de su mercado y se ajusta en mayor medida a las características de sus clientes. En cambio, Amovens no ha mostrado ninguna preferencia sobre su objetivo de mercado y presta menos atención a los clientes ya que realmente su actuación es más pasiva: responder a consultas y quejas.

\section{E.A.: «No estamos centrados en ningún segmento específico.»}

E.L.: "La gran parte de las ventas son de un distribuidor, el $75 \%-80 \%$ de nuestro mercado es británico, se está consolidando un auge importante del visitante nórdico. [...]Por lo tanto, hemos organizado cursos de inglés para los conductores.»

Los conductores juegan un multipapel en las plataformas colaborativas. Por un lado, pagan comisión por los viajes reservados, que es el ingreso principal de este negocio para las

8. La desviación típica de la valoración de la Pregunta 5 cuenta con 2,01 de Amovens y 1,6 de Lucentum Autos, ambas son las más altas de su grupo. 
plataformas. Por otro lado, son los prestadores reales del servicio, construyen la marca de las plataformas juntos con las empresas colaborativas (ver Figura 2).

Figura 2: Resultados de pasajeros para las preguntas principales

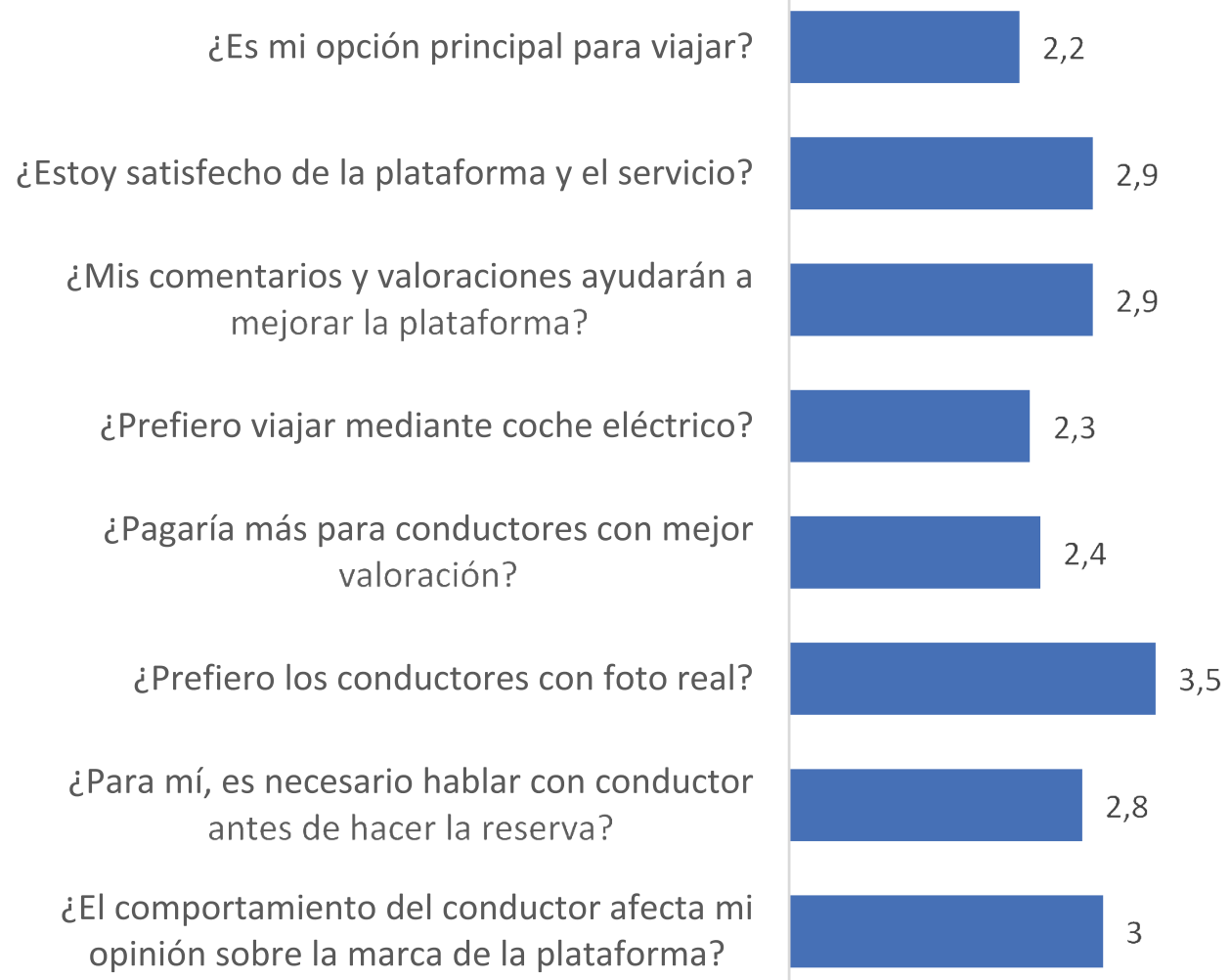

Todos los empleados encuestados de Amovens están de acuerdo en que la calidad del servicio prestado por los conductores es la clave para la empresa. Sin embargo, según las respuestas de los conductores ${ }^{9}$ (ver Figura 3 ), las plataformas no han establecido una buena conexión con ellos. En cambio, con notas más altas que Amovens, para los conductores de Lucentum Autos, la empresa tradicional no sólo ha creado una conexión satisfactoria, sino hace que ellos sean un componente positivo para la gestión de calidad según todos los aspectos.

9. Por la similitud e indiferencia entre BlaBlaCar y Amovens, y la dificultad de localizar los conductores, al analizar los resultados, se unen las respuestas de conductores de las dos plataformas pare representar la situación general del sector. 
Figura 3: Comparación de resultados de conductores

- Plataformas Colaborativas $\quad$ Lucentum Autos

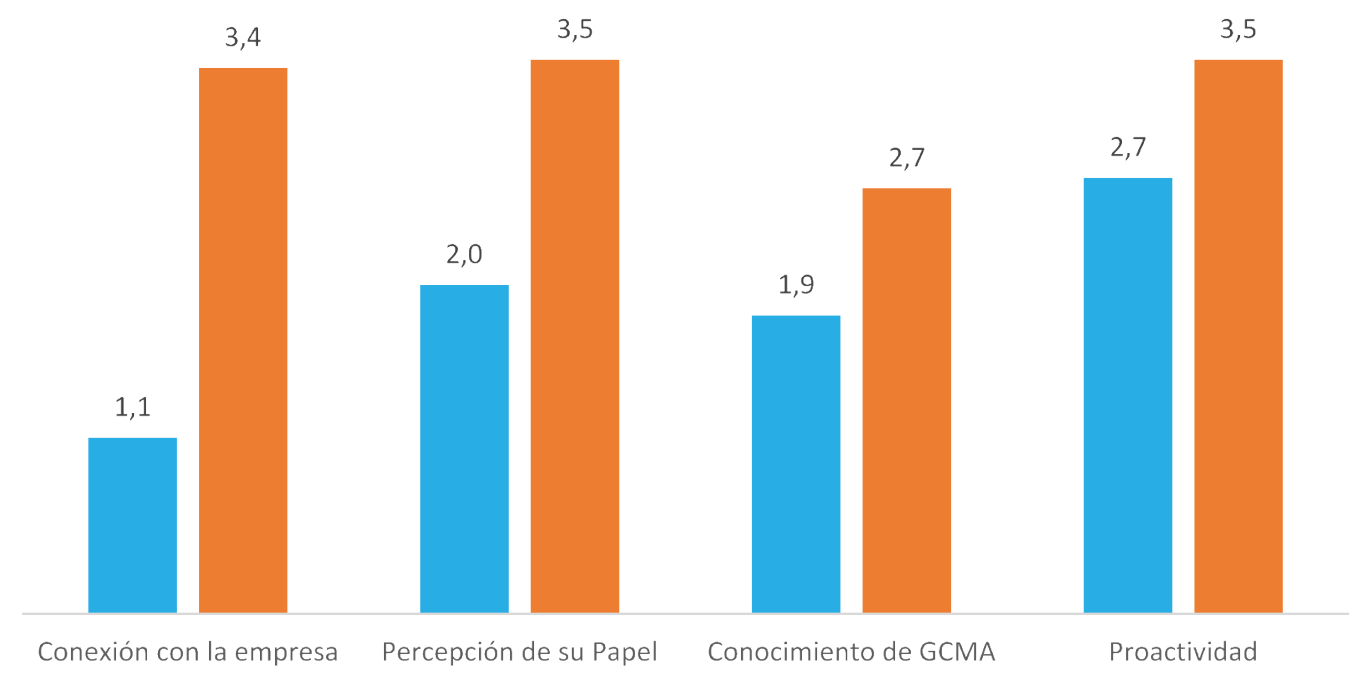

La conexión entre las empresas y los conductores es la base para su gestión del servicio. Se considera que la mala percepción de su papel, pocos conocimientos de GCMA y ser menos proactivos son las consecuencias de esa conexión deficiente. Hay que tener en cuenta que las empresas colaborativas tienen más dificultades para establecer una buena conexión con sus usuarios proveedor, ya que ellos no son sus propios empleados.

E.L.: «Nos vemos cada día en la oficina, todos somos amigos, muchos conductores ya han trabajado muchos años en la empresa.»

Uno de los dos conductores de Amovens: «Me ha llamado por teléfono una vez para solucionar mi consulta sobre el pago, pero ya hace mucho tiempo." El otro conductor de Amovens señala: «Nunca he tenido un contacto personal con la plataforma».

Amovens ya había adoptado ciertas medidas para mejorar la relación con ellos, una de ellas ha sido mencionada varias veces durante las sesiones:

E.A.: «El verano pasado, en Atocha que es el punto más popular en Madrid para quedar los conductores y pasajeros. Repartimos muchas botellas de agua a los conductores.»

Cabe señalar que la debilidad de conexión no sólo se refleja en la frecuencia, sino más bien en la calidad. En las entrevistas, todos destacaron que Amovens es «una plataforma más completa que su rival por ofrecer más opciones para viajar en coche». Lamentablemente, ningún usuario ha identificado la citada diferencia, sólo han señalado la diferencia principal del precio (ver Figura 4). La información que Amovens desea trasmitir no ha sido recibida por el público. 
Figura 4: Resultado de usuarios sobre las diferencias entre BlaBlaCar y Amovens

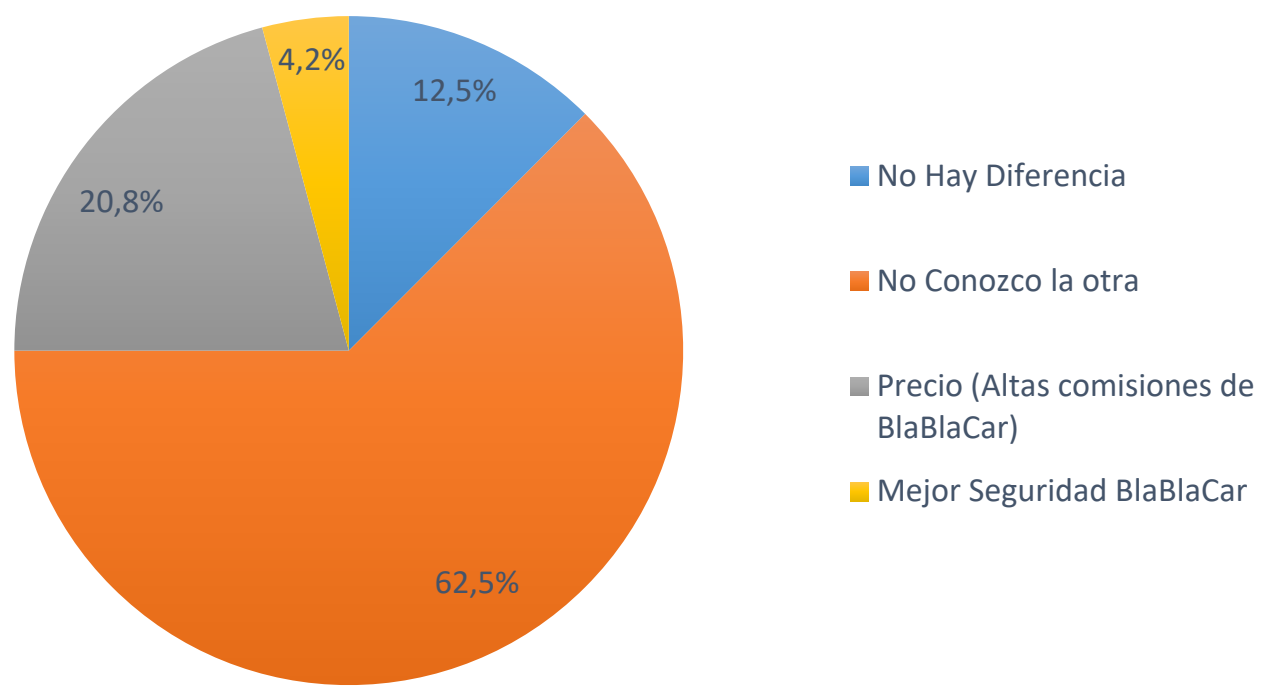

La alta evaluación dada por los propios empleados de Amovens indica que la plantilla considera su gestión de los grupos de interés sobresaliente. Pero las respuestas de sus usuarios no han mostrado una situación correspondiente. Estas diferentes percepciones también revelan el fallo de la comunicación entre ellos.

\subsubsection{Información y Análisis}

Aunque en ambas empresas las TICs han sido integradas profundamente, hay diferencias. En Lucentum destaca la introducción de un sistema digital de gestión de vehículos, E-VTC, con el cual los administrativos pueden obtener información en tiempo real de cada vehículo y conductor, que incluye la ubicación, velocidad, el consumo de combustibles, etc. Ha sido la medida principal para la administración para evaluar la eficiencia de los conductores. Cada uno tiene accesos correspondientes para ver diferentes informes según su puesto. Con esta información, los conductores pueden evaluar su propio trabajo para mejorar su servicio.

Además, al saber que muchos conductores tienen dificultad para acceder al sistema por la falta de dispositivos, los administradores les informan de los resultados de forma periódica y proactiva. La empresa hace lo posible para asegurar que cada conductor reciba y entienda sus resultados. Esta serie de prácticas hace de Lucentum una pionera ante sus rivales.

$$
\begin{aligned}
& \text { E.L.: "De nuestro tamaño, somos la única empresa que usa el sistema (en } \\
& \text { España).» }
\end{aligned}
$$


En Amovens, los empleados muestran una fuerte intención de usar datos para tomar decisiones, ya que la empresa les facilita herramientas para obtenerlos y compartir los resultados.

E.A.: «Usamos Google Drive para guardar documentos, donde podemos encontrar planes, $\mathrm{KPl}$, datos...Cada uno tiene acceso a carpetas relacionadas a su trabajo. [...] Antes de plantear una campaña, tenemos que buscar informaciones, datos, informes relacionados...»

Sin embargo, el uso de TICs en Amovens se queda en un nivel básico.

\subsubsection{Productos/servicios}

Los pasajeros han manifestado la necesidad de la comunicación pre-reserva (ver Figura 5). Con todo, antes de mayo de 2018 , no se encontraba ningún botón directo para hablar con los conductores en la página de viaje, sino que había que entrar al perfil del conductor, así requería más pasos (ver Figura 6, botón «Enviar»).

Figura 5: Resultado de pasajeros sobre «para mí, ¿es necesario hablar con conductor antes de hacer la reserva?»

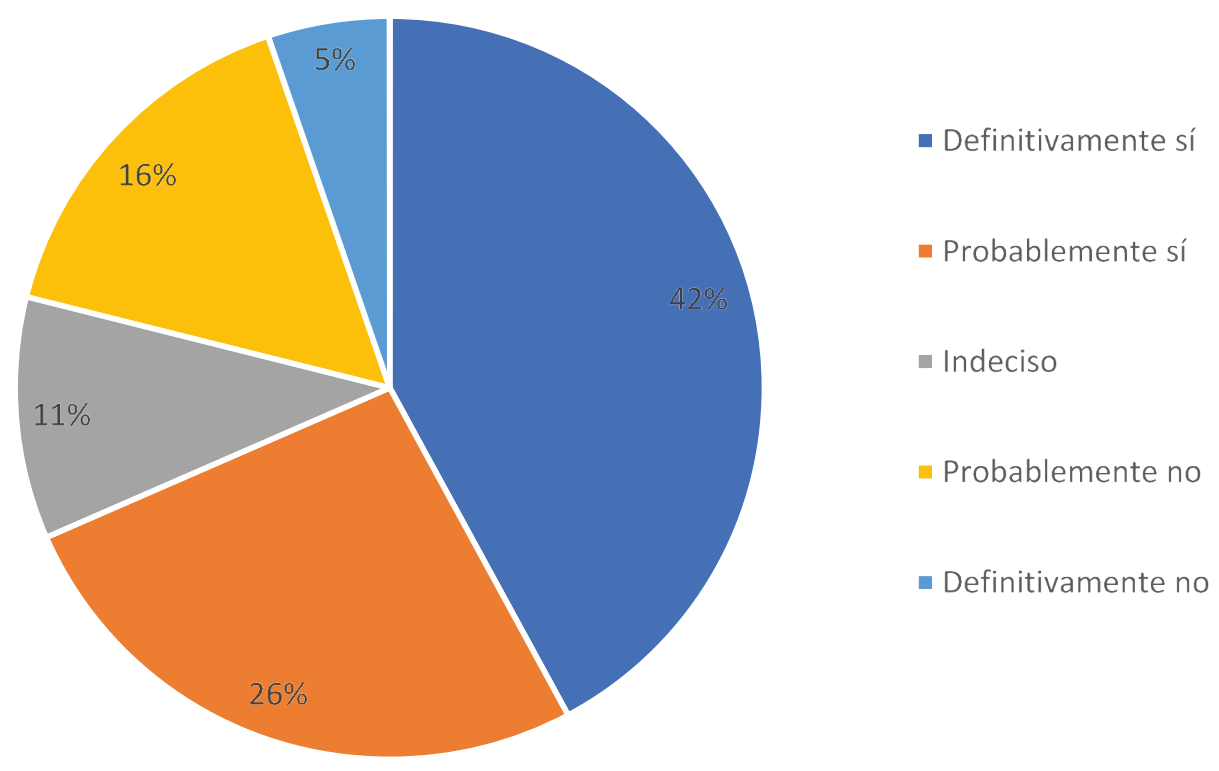


Figura 6: Comparación entre versiones de Amovens con/sin acceso directo para contactar con conductor

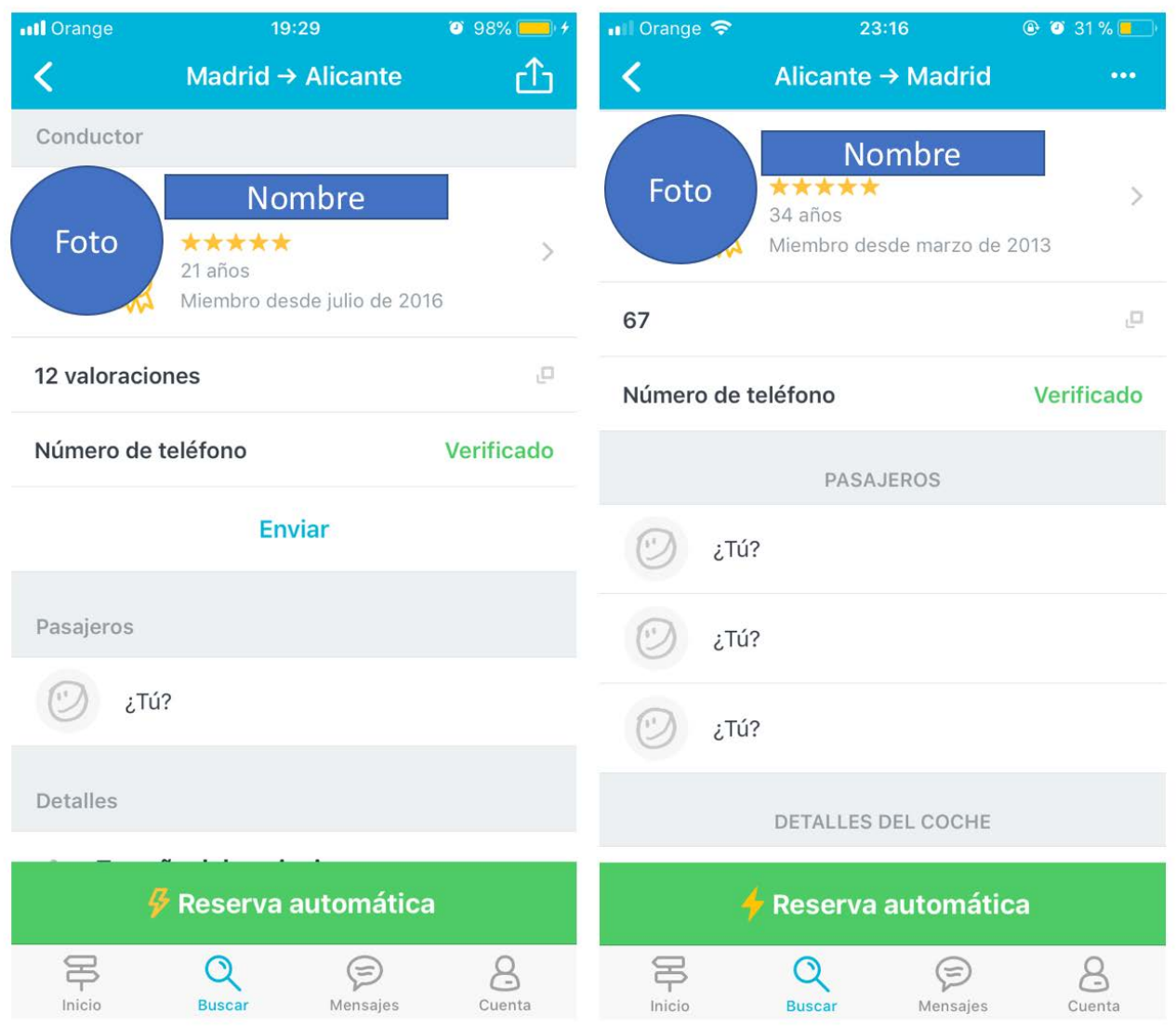

Fuerte: Elaboración propia a partir de las capturas de pantalla que se realizaron el 14 de marzo (derecha) y el 15 de mayo (izquierda) de 2018 en la APP Amovens (versiones de IOS) respectivamente.

Al contrario, Lucentum Autos se muestra más sensible a sus clientes.

E.L.: "Miramos cada reserva...las informaciones de clientes, y asignamos conductores con mejor valoración a los clientes más importantes. [...] Los conductores que hablan bien inglés suelen ser asignados a extranjeros.»

El medio ambiente apenas ha sido mencionado en la gestión en Amovens, pero en su aplicación, se ha introducido el indicador Ahorro de $\mathrm{CO}_{2}$ en la página del perfil de usuario que señala la cantidad de $\mathrm{CO}_{2}$ ahorrada en función de la distancia total de sus viajes realizados por compartir coche de pasajero o conductor.

\section{E.A.: «Compartir coche ya es una actividad ecológica.»}

No obstante, todavía se espera una aplicación que promocione más la sostenibilidad. Por ejemplo, la gran potencia de consolidar la voluntad de viajar mediante coche eléctrico entre sus usuarios ha sido un aspecto destacado (ver Figura 7). Introducir más características medioambientales no sólo es una necesidad para satisfacer al cliente, sino que también responde a la esencia de la economía colaborativa. 
Figura 7: Resultado de pasajeros sobre «prefiero viajar mediante coche eléctrico?»

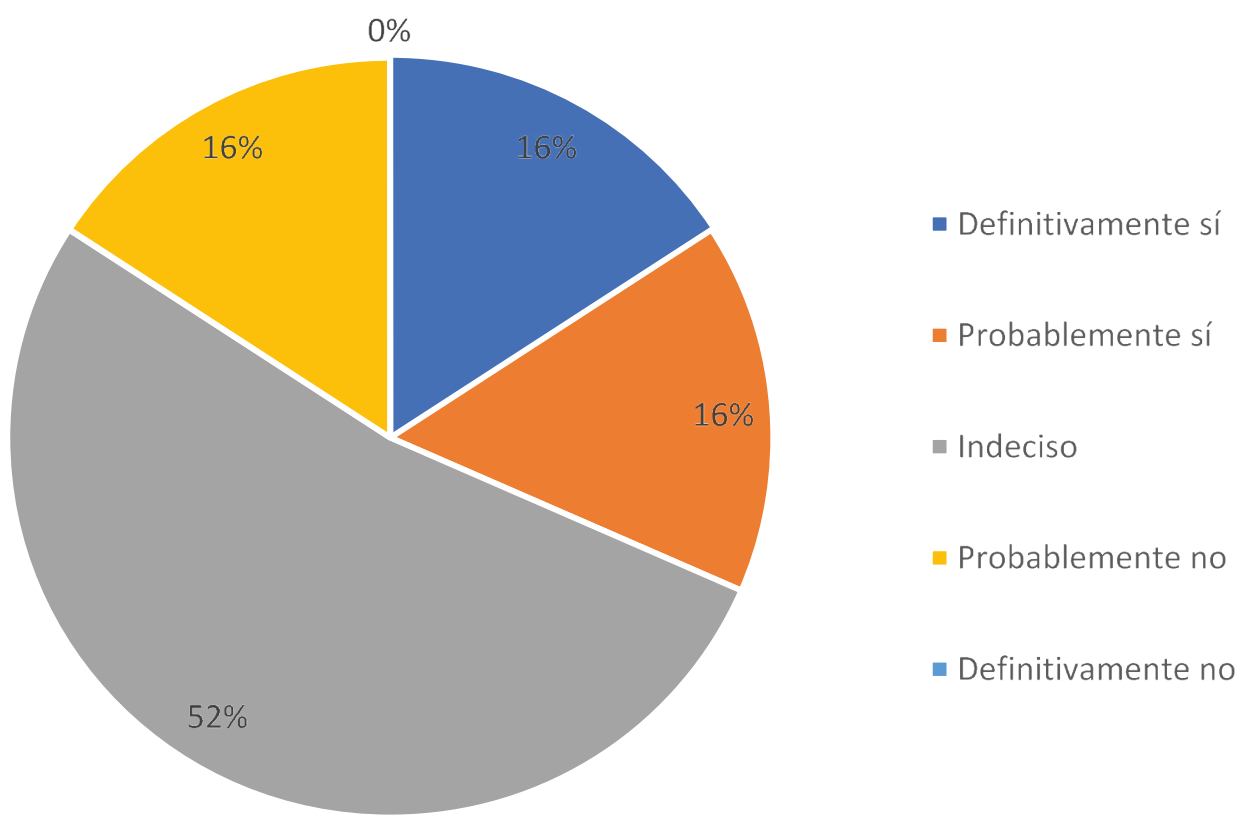

\subsubsection{Procedimientos}

El establecimiento de procesos es un factor fundamental para la implantación de un sistema de gestión. Para los compañeros del departamento de atención al cliente de Amovens existe un manual de trabajo. Todas las comunicaciones con los clientes se deben realizar cumpliendo los requisitos establecidos en este manual. Además, se han destacado otros dos procedimientos internos en las entrevistas, un proceso de evaluación de la satisfacción de empleados y un proceso de formación. Respecto a los procedimientos relacionados con las cooperaciones internas, los canales informales se han convertido en la manera principal de comunicación diaria entre empleados de Amovens.

E.A.: «A menos que sean problemas claves, normalmente hablamos con el responsable o la persona relacionada cara a cara.»

Existe el mismo problema en Lucentum Autos. De este modo, la comunicación verbal suele ser más rápida y clara, pero no se registra. La información puede perderse o distorsionarse debido a diferentes entendimientos y re-expresiones, y este aspecto podría ser un área de mejora.

Para examinar este problema, se ha pedido a los encuestados dos informaciones básicas y críticas que respectivamente responden al conocimiento de mercado y la satisfacción de clientes:

«¿Cuándo es la temporada alta del negocio de coche compartido?»

«¿Cuál es la valoración media entre usuarios?» 
Se han obtenido diferentes respuestas. En la primera, algunos creyeron que es el verano, agosto en particular, otros respondieron lo contrario. En la segunda, la valoración media es de 4,8 , pero había otras respuestas.

Tanto Amovens como Lucentum realizan todos sus procedimientos de forma digital. La primera dispone de una mejor competencia en las TICs y los recursos humanos para realizarlo. Lo que falta es reducir la comunicación verbal. La comunicación ha sido identificada como un aspecto a mejorar por segunda vez, antes era de la plataforma y los usuarios, y esta vez entre sus propios empleados. Esto refuerza la idea de que la comunicación es un punto de mejora crítico.

\subsubsection{Proveedores}

Para Lucentum Autos, el consumo crítico es el combustible de su flota, y para Amovens, es el mantenimiento del servidor y los suministros de material de oficina, como papel, bebida, etc. A partir de las respuestas, Lucentum hace esfuerzos por adaptar las necesidades de sus proveedores para mantener una relación larga y estable con ellos, pero Amovens no muestra una preocupación por la gestión de los proveedores.

En la economía tradicional, los proveedores tienen un mayor impacto en la rentabilidad que en la economía colaborativa. Una plataforma colaborativa responsable debería tener una visión más amplia y considerar los consumos de sus usuarios. En este sentido, para mejorar su gestión en esta dimensión, las empresas colaborativas puedan buscar mejores productos y servicios para sus usuarios para realizar las actividades colaborativas, como la búsqueda de productos ecológicos y económicos, difusión de técnicas de conducir para reducir el consumo de gasolina, etc.

Estos resultados para cada uno de los principios o dimensiones de la calidad muestran la situación de la empresa Amovens y ayudan a tener una visión general del sector del turismo colaborativo español, incluso de la economía colaborativa española, dado el limitado número y tamaño de empresas de este modelo en España.

Amovens dispone de un equipo más dinámico y con mejor conocimiento de las TICs y datos, la dirección aplica una gestión más moderna y tiene unas políticas de formación más avanzadas. La plataforma mantiene un buen nivel de gestión y una alta satisfacción de usuarios.

La empresa colaborativa ha dejado alta autonomía a los usuarios, los conductores y pasajeros, y se asegura la confianza entre ellos. La plantilla centra su mayor esfuerzo en ofrecer una plataforma estable y eficiente, y crear una marca diferenciadora. Como consecuencia, ha reducido muchos procedimientos de control. Además, su estructura reducida ha provocado un crecimiento explosivo, pero también se ha convertido en un factor más incontrolable que hace más importante el cumplimiento de los principios de la gestión de la calidad. Junto a estos aspectos, esta investigación destaca los siguientes problemas a tener en cuenta:

1. La baja atención al tema medioambiental.

2. La ineficiencia de la comunicación verbal.

3. La demora en responder a las necesidades de los usuarios.

4. La débil conexión con los conductores (es la más crítica). 


\subsection{Nuevos criterios para las empresas colaborativas turísticas}

A partir de estos problemas observados en este trabajo y la comparación de la situación de las dimensiones de la gestión de la calidad (Molina-Azorín et al., 2009; Tarí, 2005) identificadas en el sector del turismo colaborativo y en el sector del turístico tradicional, se proponen los nuevos criterios para implantar un sistema de gestión en empresas colaborativas turísticas (ver Tabla 3), que pueda mejorar tanto la calidad como el medio ambiente.

Tabla 3: Nuevos criterios del sistema de gestión para EE.CC.TT.

\begin{tabular}{|c|c|}
\hline DIMENSIÓN & REQUISITOS \\
\hline Personas & $\begin{array}{l}\text { Aplicar una estructura organizativa horizontal con menos jerarquías. La } \\
\text { dirección está comprometida con la mejora continua de la calidad y el } \\
\text { medio ambiente, participa en las actividades relacionadas. Establecer } \\
\text { un equipo responsable de la gestión y asignar los recursos necesarios. } \\
\text { Introducir los resultados de gestión en la remuneración. Medir la } \\
\text { satisfacción de empleados de forma sistemática y ofrecer programas de } \\
\text { formación adaptados a las necesidades personales y profesionales de la } \\
\text { plantilla. }\end{array}$ \\
\hline $\begin{array}{l}\text { Políticas y } \\
\text { Planificación }\end{array}$ & $\begin{array}{l}\text { Formular y publicar políticas claras dedicadas a la mejora de la calidad y el } \\
\text { medio ambiente, y un plan comprensivo que se actualice según el desarrollo } \\
\text { de la empresa. Comunicación de los avances periódicamente a toda la } \\
\text { plantilla. }\end{array}$ \\
\hline Procedimientos & $\begin{array}{l}\text { Crear una intranet para realizar o iniciar todos los procedimientos. } \\
\text { Establecer procedimientos adaptando las necesidades de empleados, } \\
\text { usuarios y otros grupos de interés. Tener en cuenta las incidencias y } \\
\text { las novedades. Guardarlos y mostrarlos en la intranet. Registrar las } \\
\text { comunicaciones necesarias. }\end{array}$ \\
\hline Datos y Análisis & $\begin{array}{l}\text { Introducir herramientas para obtener y analizar los datos y ofrecer } \\
\text { formación pertinente. Usar los datos para tomar decisiones y analizar los } \\
\text { efectos de las actividades. }\end{array}$ \\
\hline Usuarios & $\begin{array}{l}\text { Considerar a los usuarios proveedor la clave de la marca de la plataforma, y } \\
\text { mantener en contacto con ellos. Nombrar un responsable que se encargue } \\
\text { de la mejora de la relación con ellos. Evaluar la satisfacción de los usuarios } \\
\text { periódicamente y comunicar los resultados a toda la plantilla. Comunicar las } \\
\text { políticas de calidad y medio ambiente a los usuarios de forma proactiva y } \\
\text { facilitar recursos para que puedan participar en la mejora. }\end{array}$ \\
\hline Productos / Servicios & $\begin{array}{l}\text { Animar a la plantilla a usar sus propios productos o servicios. Recoger } \\
\text { opiniones de usuarios de forma sistemática y proactiva. Diseñar las } \\
\text { características de las aplicaciones respondiendo a las necesidades de } \\
\text { usuarios y los principios de la gestión. Reducir los fallos/errores y actualizar } \\
\text { productos/servicios periódicamente. }\end{array}$ \\
\hline Grupos de interés & $\begin{array}{l}\text { Modificar los procesos y políticas según las necesidades de proveedores. } \\
\text { Evaluar los indicadores de calidad/precio y medio ambiente al seleccionar } \\
\text { proveedores para la empresa, y también buscar soluciones más económicas } \\
\text { y medioambientales para los usuarios, especialmente los usuarios } \\
\text { proveedor. Crear relaciones más agradables entre usuarios y otros grupos } \\
\text { afectados. }\end{array}$ \\
\hline
\end{tabular}


En estos nuevos criterios, se pide prestar más atención a los siguientes aspectos: reducir la jerarquía y crear puestos responsables de la gestión, los usuarios (proveedores y consumidores) porque son su objetivo básico (especialmente hay que tener en cuenta el multipapel de los usuarios proveedor), buscar mejores proveedores tanto para su funcionamiento como para sus usuarios, considerar el medio ambiente como un aspecto tan importante como el económico.

\section{CONCLUSIONES}

Este artículo ha analizado el sistema de gestión en organizaciones colaborativas del sector turístico a partir de los principios o dimensiones de la calidad (primer objetivo) y propone criterios clave para mejorar su gestión (objetivo 2 ) teniendo en cuenta las dimensiones de la calidad y la comparación entre una empresa de turismo colaborativo y otra de turismo tradicional.

Esta investigación ofrece una perspectiva nueva para la comunidad académica sobre la economía colaborativa destacando la reorientación de su enfoque desde un desarrollo de la rapidez a la calidad, tanto para las empresas como para las administraciones. Los resultados ayudan a los directivos a identificar y evitar sus problemas y mejorar su gestión siguiendo los nuevos criterios enumerados en la Tabla 3. Para Amovens, se recomiendan las siguientes iniciativas para mejorar su gestión:

1. Crear un puesto nuevo en la empresa para mejorar la gestión, y de esta forma empezar a introducir un sistema de gestión utilizando como guía las dimensiones de la calidad.

2. Optimizar la conexión con los conductores. Para ello puede nombrar a un responsable de esta tarea.

3. Crear una comunicación periódica para los usuarios donde se publiquen los productos económicos y sostenibles para el coche, cupones de descuentos, promociones de gasolineras, recomendaciones de viaje y otras informaciones relacionadas con su negocio.

4. Establecer procedimientos estándares y formales de comunicación interna.

5. Realizar un estudio de los usuarios y del mercado.

El trabajo utiliza una muestra limitada de los grupos de interés debido a las limitaciones de tiempo y recursos. Por la misma razón, tampoco ha seleccionado más empresas colaborativas para el estudio. En las investigaciones futuras, se pueden realizar un mayor número de encuestas y entrevistas a los usuarios y ampliar este estudio a más subsectores colaborativos y otras regiones.

\section{REFERENCIAS}

Abad, J., Dalmau, I., \& Vilajosana, J. (2014). Taxonomic proposal for integration levels of management systems based on empirical evidence and derived corporate benefits. Journal of Cleaner Production, 78, 164-173. https://doi.org/10.1016/J.JCLEPRO.2014.04.084

AEC. (1997). Cuestionario para medir la gestión de la calidad. 
AirDNA. (2019). Real Estate Investing with Airbnb, Market Analysis for Alicante - AirDNA MarketMinder. Recuperado 22 de enero de 2019, de https://www.airdna.co/ vacation-rental-data/app/es/alicante/alicante-alacant/overview

Amovens. (2018). Alquila coche y comparte viaje con Amovens. Recuperado 7 de mayo de 2018, de https://amovens.com/

Angell, L. C., \& Klassen, R. D. (1999). Integrating environmental issues into the mainstream: an agenda for research in operations management. Journal of Operations Management, 17(5), 575-598. https://doi.org/10.1016/S0272-6963(99)00006-6

Beckmerhagen, I. A., Berg, H. P., Karapetrovic, S. V., \& Willborn, W. O. (2003). Integration of management systems: focus on safety in the nuclear industry. International Journal of Quality \& Reliability Management, 20(2), 210-228. https://doi. org/10.1108/02656710310456626

Belk, R. (2014). You are what you can access: Sharing and collaborative consumption online. Journal of Business Research, 67(8), 1595-1600. https://doi.org/10.1016/j. jbusres.2013.10.001

Beltran Cangròs, A. (2018). Plataformas de economía colaborativa: una mirada global.

Bernardo, M., Simon, A., Tarí, J. J., \& Molina-Azorín, J. F. (2015). Benefits of management systems integration: a literature review. Journal of Cleaner Production, 94, 260-267. https://doi.org/10.1016/J.JCLEPRO.2015.01.075

BlaBlaCar. (2018). Dossier de Prensa España 2017.

Botsman, R., \& Rogers, R. (2010). Beyond Zipcar: Collaborative Consumption. Harvard business review, 88(10), 30.

Centro de Investigación de la Economía Colaborativa del Centro Estatal de Información Chino, \& Comisión de la Economía Colaborativa de Sociedad de Internet de China. (2018). 中国共享经济发展年度报告 [Informe Anual Sobre El Desarrollo de La Economía Colaborativa de China]. Beijing.

Cervero, R., Golub, A., \& Nee, B. (2007). City CarShare longer-term travel demand and car ownership impacts. Transportation Research Record, 1992(1), 70-80. https://doi. org/10.3141/1992-09

Comisión Europea. (2014). REGLAMENTO (UE) № 651/2014 de la Comisión. Diario Oficial de la Unión Europea. Bruselas.

Crowder, M. (2013). Quality standards: integration within a bereavement environment. The TQM Journal, 25(1), 18-28. https://doi.org/10.1108/17542731311286405

Curkovic, S. (2003). Environmentally Responsible Manufacturing: The development and validation of a measurement model. European Journal of Operational Research, 146(1), 130-155. https://doi.org/10.1016/S0377-2217(02)00182-0

de Oliveira, O. J. (2013). Guidelines for the integration of certifiable management systems in industrial companies. Journal of Cleaner Production, 57, 124-133. https://doi. org/10.1016/J.JCLEPRO.2013.06.037

del Castillo, C. (2017). Uber: «En España, Uber no es economía colaborativa» | Público. Recuperado 5 de febrero de 2019, de https://www.publico.es/sociedad/uber-espana-uber-economia-colaborativa.html 
El Confidencial. (2017). Uber: Taxistas contra Uber y Cabify: el porqué de la huelga y sus culpables. Recuperado 22 de enero de 2019, de https://www.elconfidencial.com/ espana/2017-05-30/que-piden-taxistas-por-que-huelga-uber-cabify 1390685/

Ferreira Rebelo, M., Santos, G., \& Silva, R. (2014). A generic model for integration of Quality, Environment and Safety Management Systems. The TQM Journal, 26(2), 143-159. https://doi.org/10.1108/TQM-08-2012-0055

Franco, L., \& Gómez, D. (2019). Los taxistas no llegan a un acuerdo con la Comunidad y se plantean si continúan la huelga | Madrid | EL PAís. Recuperado 5 de febrero de 2019, de https://elpais.com/ccaa/2019/02/04/madrid/1549310722 718275.html

Hamari, J., Sjöklint, M., \& Ukkonen, A. (2016). The Sharing Economy: Why People Participate in Collaborative Consumption. Journal of the Association for Information Science and Technology (Vol. 67). https://doi.org/10.1002/asi.23552

HOSBEC. (2018). El impacto del alojamiento Airbnb en Benidorm.

INE. (2018). Cuenta Satélite del Turismo de España (CSTE). Recuperado 10 de enero de 2019, de https://www.ine.es/dyngs/INEbase/es/operacion. htm?c=Estadistica_C\&cid=1254736169169\&menu=ultiDatos\&idp=1254735576863

INE. (2019). Empresas por condición jurídica, actividad principal (grupos CNAE 2009) y estrato de asalariados. Recuperado 6 de febrero de 2019, de http://www.ine.es/jaxiT3/Datos. htm?t=297

Juzgado de lo Mercantil Nº 02 de Madrid. Sentencia N³0/2017 (2017).

Karapetrovic, S., \& Casadesús, M. (2009). Implementing environmental with other standardized management systems: Scope, sequence, time and integration. Journal of Cleaner Production, 17(5), 533-540. https://doi.org/10.1016/J.JCLEPRO.2008.09.006

Klassen, R. D., \& McLaughlin, C. P. (1993). TQM and Environmental Excellence in Manufacturing. Industrial Management \& Data Systems, 93(6), 14-22. https://doi.org/10.1108/ 02635579310040924

Knowledge@Wharton. (2016). De Peerby a SnappCar: la economía compartida en Europa Universia Knowledge@Wharton. Recuperado 5 de febrero de 2019, de https://www. knowledgeatwharton.com.es/article/peerby-snappcar-la-economia-compartidaeuropa/

Kriptón Inteligencia（氪星情报局）.(2018). 滴滴打车越来越贵? 这份年终盘点，让我深 感再也“打不起车”了! [¿Viajar con Didi ha sido cada vez más caro? Este inventario de fin de año me hace sentir que ya «no puedo pagar el viaje».]. Recuperado 1 de febrero de 2019, de http://tech.caijing.com.cn/20180110/4391855.shtml

Li, K. (2017). Informe sobre la labor del gobierno. En la V Sesión de la XII Asamblea Popular Nacional. Beijing.

Minifie, J., \& Wiltshire, T. (2016). Peer-to-peer pressure: policy for the sharing economy.

Molina-Azorín, J. F., Tarí, J. J., Claver-Cortés, E., \& López-Gamero, M. D. (2009). Quality management, environmental management and firm performance: A review of empirical studies and issues of integration. International Journal of Management Reviews, 11(2), 197-222. https://doi.org/10.1111/i.1468-2370.2008.00238.x

Nielson. (2014). La Crisis Lleva A Más De La Mitad De Los Españoles A Querer Compartir O Alquilar Bienes. Recuperado 9 de febrero de 2019, de https://www.nielsen.com/es/es/ 
press-room/2014/la-crisis-lleva-a-mas-de-la-mitad-de-los-espanoles-a-querer-comp. html

PwC. (2015). The Sharing Economy - Consumer Intelligence Series.

Rodríguez, M. An., \& Ricart, J. E. (2000). Coordinación de los sistemas de gestión de calidad, medio ambiente y salud laboral (parte I). Harvard Deusto business review, (97), 54-60.

Santos, G., Mendes, F., \& Barbosa, J. (2011). Certification and integration of management systems: the experience of Portuguese small and medium enterprises. Journal of Cleaner Production, 19(17-18), 1965-1974. https://doi.org/10.1016/J.JCLEPRO.2011.06.017

Sharing España. (2017). Los Modelos Colaborativos Y Bajo Demanda en Plataformas DIgitales. Madrid.

Simon, A., \& Douglas, A. (2013). Integrating management systems: does the location matter? International Journal of Quality \& Reliability Management, 30(6), 675-689. https://doi. org/10.1108/02656711311325629

Simon, A., Karapetrovic, S., \& Casadesus, M. (2012). Evolution of Integrated Management Systems in Spanish firms. Journal of Cleaner Production, 23(1), 8-19. https://doi. org/10.1016/J.JCLEPRO.2011.10.025

Simon, A., Karapetrovic, S., \& Casadesús, M. (2012). Difficulties and benefits of integrated management systems. Industrial Management \& Data Systems, 112(5), 828-846. https://doi.org/10.1108/02635571211232406

Tarí, J. J. (2005). Components of successful total quality management. TQM Magazine, 17(2), 182-194. https://doi.org/10.1108/09544780510583245

TeleMadrid. (2019). Los taxistas madrileños estudian demandar a las VTC por «competencia desleal». Recuperado 5 de febrero de 2019, de http://www.telemadrid.es/ programas/telenoticias-fin-de-semana/estudia-demandar-VTC-competencia-desleal-2-2091410847--20190202023815.html

The Economist. (2013). The rise of the sharing economy. Recuperado 15 de enero de 2019, de https://www.economist.com/news/leaders/21573104-internet-everything-hire-rise-sharing-economy

Wagner, M. (2007). Integration of Environmental Management with Other Managerial Functions of the Firm: Empirical Effects on Drivers of Economic Performance. Long Range Planning, 40(6), 611-628. https://doi.org/10.1016/J.LRP.2007.08.001

Walsh, B. (2011). Today's Smart Choice: Don't Own. Share - 10 Ideas That Will Change the World. Recuperado 15 de enero de 2019, de http://content.time.com/time/specials/ packages/article/0,28804,2059521 2059717,00.html

Wilkinson, G., \& Dale, B. G. (1999). Integrated management systems: an examination of the concept and theory. The TQM Magazine, 11(2), 95-104. https://doi. org/10.1108/09544789910257280

World Bank. (2018). GDP (current US\$). Recuperado de https://data.worldbank.org/indicator/ NY.GDP.MKTP.CD?year high desc=true

Yin, B., Liu, L., Coulombel, N., \& Viguié, V. (2018). Appraising the environmental benefits of ride-sharing: The Paris region case study. Journal of Cleaner Production, 177, 888-898. https://doi.org/10.1016/i.jclepro.2017.12.186 
Zeng, S. X., Tian, P., \& Shi, J. J. (2005). Implementing integration of ISO 9001 and ISO 14001 for construction. Managerial Auditing Journal, 20(4), 394-407. https://doi. org/10.1108/02686900510592070

Zervas, G., Proserpio, D., \& Byers, J. (2013). The Rise of the Sharing Economy: Estimating the Impact of Airbnb on the Hotel Industry. SSRN Electronic Journal. https://doi. org/10.2139/ssrn.2366898

Zutshi, A., \& Sohal, A. S. (2005). Integrated management system. Journal of Manufacturing Technology Management, 16(2), 211-232. https://doi. org/10.1108/17410380510576840 


\section{ANEXO 1: ENCUESTA PARA AMOVENS}

\section{CUESTIONARIO SOBRE LA GESTIÓN DE CALIDAD Y MEDIO AMBIENTE}

(Amovens)

Por favor, marque las casillas con solamente una $\mathrm{X}$ según la situación real:

0 : Prácticamente no se realiza

1: Se realiza parcialmente (en ocasiones puntuales)

2: Se realiza generalmente (en la mayoría de los casos)

3: Se realiza sistemáticamente y en casi todas las áreas

4: Se realiza siempre y de forma total, y somos un ejemplo para el sector.

\begin{tabular}{|c|c|c|c|c|c|c|}
\hline No. & Preguntas & 0 & 1 & 2 & 3 & 4 \\
\hline 1 & $\begin{array}{l}\text { ¿Conozco los principios de la gestión de calidad y medio ambiente, y } \\
\text { estoy comprometido con ellos, dando y recibiendo formación sobre los } \\
\text { mismos, y dando ejemplo con mi forma de actuar? }\end{array}$ & & & & & \\
\hline 2 & ¿Me estimula identificar y solucionar problemas de mi trabajo? & & & & & \\
\hline 3 & $\begin{array}{l}\text { ¿Impulso y apoyo las actividades de mejora dentro de la organización y } \\
\text { con viajeros y conductores? }\end{array}$ & & & & & \\
\hline 4 & ¿Tenemos canales para dar sugerencias a la dirección fácilmente? & & & & & \\
\hline 5 & $\begin{array}{l}\text { ¿Se evalúa y recompensa los resultados sobre la calidad y medio } \\
\text { ambiente? }\end{array}$ & & & & & \\
\hline 6 & $\begin{array}{l}\text { ¿Conozco los objetivos y planes de la empresa y se nos facilitan medios } \\
\text { para que podamos cumplirlos? }\end{array}$ & & & & & \\
\hline 7 & $\begin{array}{l}\text { ¿Entiendo que toda la plantilla es responsable de la mejora de calidad y } \\
\text { medio ambiente? }\end{array}$ & & & & & \\
\hline 8 & ¿La dirección también participa en las actividades de la mejora? & & & & & \\
\hline 9 & $\begin{array}{l}\text { ¿La calidad de los servicios ofrecidos por los conductores es clave para la } \\
\text { empresa? }\end{array}$ & & & & & \\
\hline 10 & $\begin{array}{l}\text { ¿Sé dónde puedo encontrar nuestros planes, políticas y manuales de } \\
\text { trabajo? }\end{array}$ & & & & & \\
\hline 11 & $\begin{array}{l}\text { ¿Se mide de forma sistemática mi satisfacción teniendo en cuenta mis } \\
\text { necesidades y expectativas (e. g.: ambientes de trabajo, posibilidad de } \\
\text { promoción, comunicación, formación, reconocimiento)? }\end{array}$ & & & & & \\
\hline 12 & $\begin{array}{l}\text { ¿La gestión de calidad y medio ambiente es una parte de peso de } \\
\text { nuestra estrategia y políticas? }\end{array}$ & & & & & \\
\hline 13 & ¿Nuestros planes reflejan las necesidades de usuarios? & & & & & \\
\hline
\end{tabular}

Este estudio tiene el fin de evaluar los sistemas de gestión en las empresas colaborativas turísticas en España, sus datos personales serán anónimos y seguro, no los compartimos a su empresa ni al público. jGracias por su colaboración! si le interesa los resultados, puede dejar su email en la hoja. 


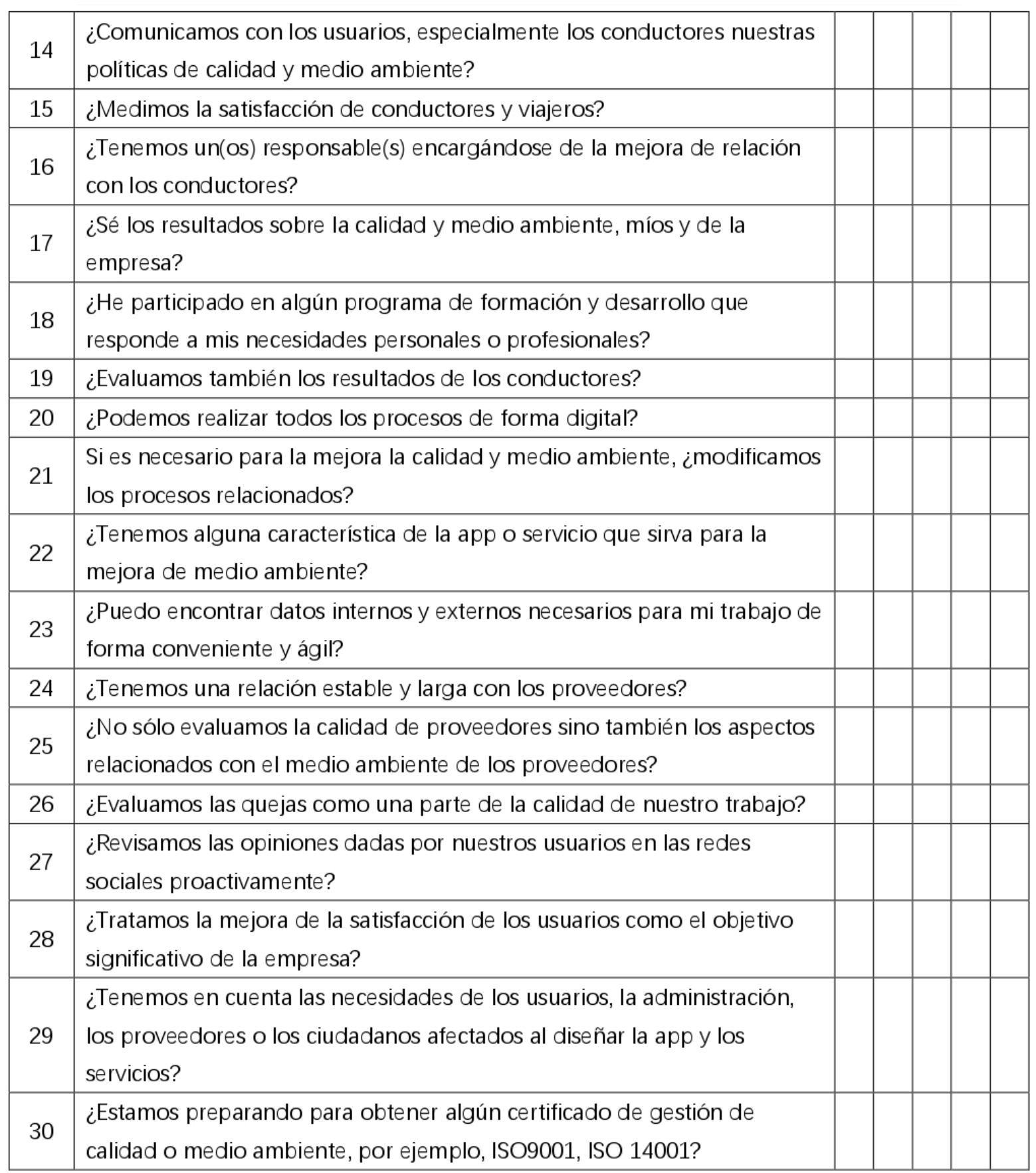

Este estudio tiene el fin de evaluar los sistemas de gestión en las empresas colaborativas turísticas en España, sus datos personales serán anónimos y seguro, no los compartimos a su empresa ni al público. iGracias por su colaboración! Si le interesa los resultados, puede dejar su email en la hoja. 


\section{ANEXO 2: ENCUESTA PARA LUCENTUM AUTOS}

\section{CUESTIONARIO SOBRE LA GESTIÓN DE CALIDAD Y MEDIO AMBIENTE}

\section{(Lucentum Autos)}

Por favor, marque las casillas con solamente una $X$ según la situación real:

\section{0 : Prácticamente no se realiza}

1: Se realiza parcialmente (en ocasiones puntuales)

2: Se realiza generalmente (en la mayoría de los casos)

3: Se realiza sistemáticamente y en casi todas las áreas

4: Se realiza siempre y de forma total, y somos un ejemplo para el sector.

\begin{tabular}{|c|c|c|c|c|c|}
\hline No. & Preguntas & 0 & 1 & 2 & 3 \\
\hline 1 & $\begin{array}{l}\text { ¿Conozco los principios de la gestión de calidad y medio ambiente, y } \\
\text { estoy comprometido con ellos, dando y recibiendo formación sobre los } \\
\text { mismos, y dando ejemplo con mi forma de actuar? }\end{array}$ & & & & \\
\hline 2 & ¿Me estimula identificar y solucionar problemas de mi trabajo? & & & & \\
\hline 3 & $\begin{array}{l}\text { ¿Impulso y apoyo las actividades de mejora dentro de la organización y } \\
\text { con viajeros y conductores? }\end{array}$ & & & & \\
\hline 4 & ¿Tenemos canales para dar sugerencias a la dirección fácilmente? & & & & \\
\hline 5 & $\begin{array}{l}\text { ¿Se evalúa y recompensa los resultados sobre la calidad y medio } \\
\text { ambiente? }\end{array}$ & & & & \\
\hline 6 & $\begin{array}{l}\text { ¿Conozco los objetivos y planes de la empresa y se nos facilitan medios } \\
\text { para que podamos cumplirlos? }\end{array}$ & & & & \\
\hline 7 & $\begin{array}{l}\text { ¿Entiendo que toda la plantilla es responsable de la mejora de calidad y } \\
\text { medio ambiente? }\end{array}$ & & & & \\
\hline 8 & ¿La dirección también participa en las actividades de la mejora? & & & & \\
\hline 9 & $\begin{array}{l}\text { ¿La calidad de los servicios prestados por los conductores es clave para la } \\
\text { empresa? }\end{array}$ & & & & \\
\hline 10 & $\begin{array}{l}\text { ¿Sé dónde puedo encontrar nuestros planes, políticas y manuales de } \\
\text { trabajo? }\end{array}$ & & & & \\
\hline 11 & $\begin{array}{l}\text { ¿Se mide de forma sistemática mi satisfacción teniendo en cuenta mis } \\
\text { necesidades y expectativas (e. g.: ambientes de trabajo, posibilidad de } \\
\text { promoción, comunicación, formación, reconocimiento)? }\end{array}$ & & & & \\
\hline 12 & $\begin{array}{l}\text { ¿La gestión de calidad y medio ambiente es una parte de peso de } \\
\text { nuestra estrategia y políticas? }\end{array}$ & & & & \\
\hline 13 & ¿Nuestros planes reflejan las necesidades de clientes? & & & & \\
\hline 14 & $\begin{array}{l}\text { ¿Comunicamos nuestras políticas de calidad y medio ambiente con } \\
\text { clientes? }\end{array}$ & & & & \\
\hline
\end{tabular}

Este estudio tiene el fin de evaluar los sistemas de gestión en las empresas colaborativas turísticas en España, sus datos personales serán anónimos y seguro, no los compartimos a su empresa ni al público. ¡Gracias por su colaboración! 


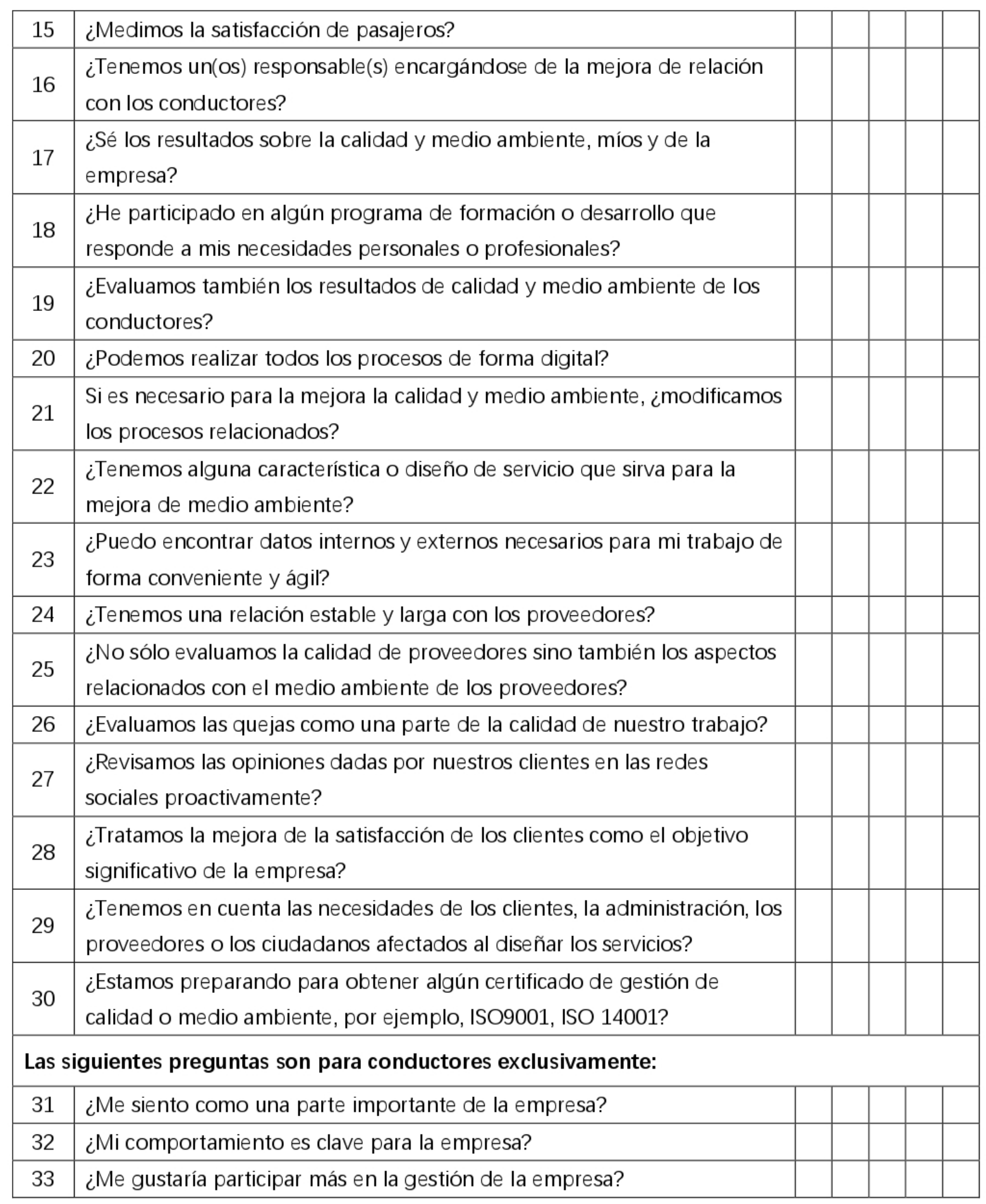

Este estudio tiene el fin de evaluar los sistemas de gestión en las empresas colaborativas turísticas en España, sus datos personales serán anónimos y seguro, no los compartimos a su empresa ni al público. ¡Gracias por su colaboración! 


\section{ANEXO 3: PREGUNTAS PARA CONDUCTORES DE LAS PLATAFORMAS COLABORATIVAS}

\section{¿Cuántos viajes al año suelo realizar en las plataformas}

$\square 1$ o menos

$\square 2-5$

$\square 6-12$

$\square$ Más de 12

Marque las siguientes preguntas según su situación real, ipor favor!

4: Definitivamente sí

3: Probablemente sí

2: Indeciso (Afirmación)

1: Probablemente no

0 : Definitivamente no

\begin{tabular}{|c|c|c|c|c|c|c|}
\hline No. & Preguntas & 0 & 1 & 2 & 3 & 4 \\
\hline 1 & ¿Me siento como una parte importante de la empresa? & & & & & \\
\hline 2 & ¿Mi comportamiento es clave para la plataforma? & & & & & \\
\hline 3 & ¿Me ha contactado alguna vez la plataforma proactivamente? & & & & & \\
\hline 4 & $\begin{array}{l}\text { ¿Conozco las políticas de la gestión de calidad y medio ambiente } \\
\text { de la plataforma? }\end{array}$ & & & & & \\
\hline 5 & $\begin{array}{l}\text { ¿La plataforma me estimula a identificar y solucionar mis propios } \\
\text { problemas? }\end{array}$ & & & & & \\
\hline 6 & ¿Tenemos canales para dar sugerencias a la plataforma? & & & & & \\
\hline 7 & $\begin{array}{l}\text { ¿La plataforma mide de forma sistemática mi satisfacción } \\
\text { teniendo en cuenta mis necesidades y expectativas? }\end{array}$ & & & & & \\
\hline 8 & ¿Me gustaría tener más conexión con la plataforma? & & & & & \\
\hline 9 & $\begin{array}{l}\text { ¿Tiene alguna característica de la aplicación que sirva para la } \\
\text { mejora de medio ambiente? }\end{array}$ & & & & & \\
\hline 10 & $\begin{array}{l}\text { ¿Me importan los comentarios y valoraciones realizados por mis } \\
\text { pasajeros? }\end{array}$ & & & & & \\
\hline 11 & ¿Me esfuerzo para mejorar mi valoración? & & & & & \\
\hline 12 & $\begin{array}{l}\text { ¿Los ingresos que recibo en cuanto a compartir coche son } \\
\text { importantes para mi economía? }\end{array}$ & & & & & \\
\hline
\end{tabular}




\section{ANEXO 4: PREGUNTAS PARA PASAJEROS DE LAS PLATAFORMAS COLABORATIVAS}

\section{¿Cuántos viajes al año suelo realizar en las plataformas}

$\square 1$ o menos

$\square 2-5$

$\square 6-12$

$\square$ Más de 12

Marque las siguientes preguntas según su situación real, ipor favor!

4: Definitivamente sí

3: Probablemente sí

2: Indeciso (Afirmación)

1: Probablemente no

0 : Definitivamente no

\begin{tabular}{|c|c|c|c|c|c|c|}
\hline No. & Preguntas & 0 & 1 & 2 & 3 & 4 \\
\hline 1 & ¿Es mi opción principal para viajar? & & & & & \\
\hline 2 & ¿Estoy satisfecho de la plataforma y el servicio? & & & & & \\
\hline 3 & $\begin{array}{l}\text { ¿Mis comentarios y valoraciones ayudarán a mejorar la } \\
\text { plataforma? }\end{array}$ & & & & & \\
\hline 4 & ¿Prefiero viajar mediante coche eléctrico? & & & & & \\
\hline 5 & ¿Pagaría más para conductores con mejor valoración? & & & & & \\
\hline 6 & ¿Prefiero los conductores con foto real? & & & & & \\
\hline 7 & $\begin{array}{l}\text { ¿Para mí, es necesario hablar con conductor antes de hacer la } \\
\text { reserva? }\end{array}$ & & & & & \\
\hline 8 & $\begin{array}{l}\text { ¿El comportamiento del conductor afecta mi opinión sobre la } \\
\text { marca de la plataforma? }\end{array}$ & & & & & \\
\hline
\end{tabular}




\section{ANEXO 5: DISEÑO DEL CUESTIONARIO PARA GRUPOS DE INTERÉS}

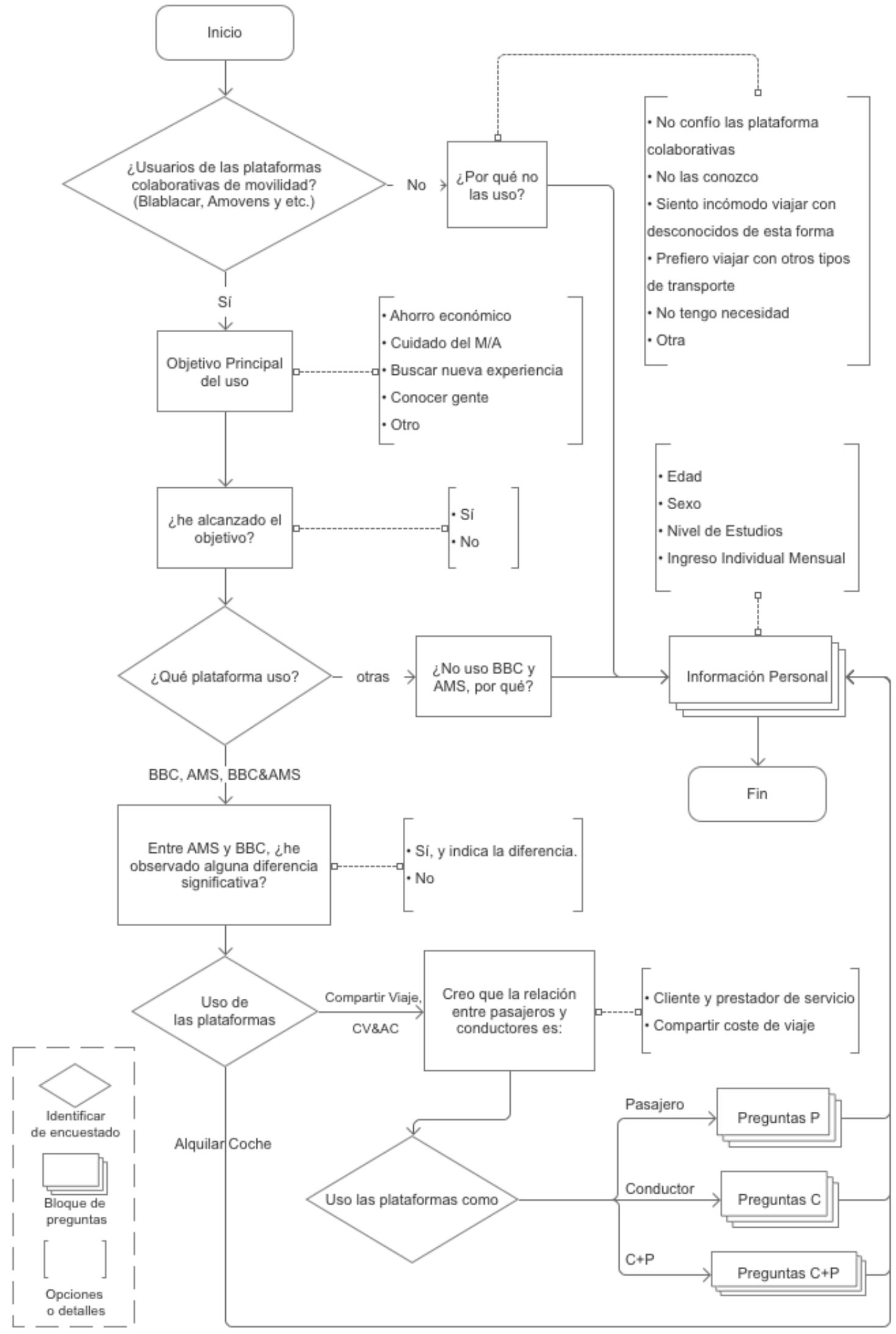

